How to Cite

Chanana, M. (2018). Empirical study: relationship between self efficacy and academic performance. International Journal of

Health \& Medical Sciences, 1(1), 28-34. https://doi.org/10.31295/ijhms.v1n1.36

\title{
Empirical Study: Relationship between Self Efficacy and Academic Performance
}

\author{
Meenakshi Chanana \\ Maharaja Agrasen Institute of Management and Technology, Jagadhri, India \\ Email: meenakshi2089@gmail.com
}

\begin{abstract}
This paper examines the relationship between the self-efficacy and academic performance in Graduation level students. The data were collected from 130 students (42 females and 88 males) selected from different semesters of undergraduate studies. To analyze data correlation and t-test analysis was used. The results of the study showed that there is a significant relationship between self-efficacy and academic performance of the students. Also, we found that there is no significant relationship between self-efficacy and academic performance among students varied by age of course. From the findings, it was recommended that teachers, Counsellors, and educators should give continuous advice and develop techniques that help lower anxiety and reduce stress, to increase student's selfefficacy.

Keywords---academic performance, age, course, gender, self-efficacy, student performance, undergraduate.
\end{abstract}

\section{Introduction}

\section{Self-Efficacy}

Self-efficacy refers to a personal judgment one makes about one's capabilities in a specific area. Self-efficacy does not refer to how much a person likes him or herself or how much he or she likes the task at hand; rather, self-efficacy is concerned with how well a person believes he or she will be able to reach the desired outcome in a designated area. "Self-efficacy represents the mechanism through which the generalized tendencies of conscientiousness manifest themselves".

Self-efficacy predicts intellectual performance better than skills alone, and it directly influences academic performance through cognition. Self-efficacy also indirectly affects perseverance. Although past achievement raises self-efficacy, it is student interpretation of past successes and failures that may be responsible for subsequent success. Perceived self-efficacy predicts future achievement better than past performance. Self-efficacy beliefs also contribute to performance since they influence thought processes, motivation, and behavior.

Academic self-efficacy has been defined "as personal judgments of one's capabilities to organize and execute courses of action to attain designated types of educational performances". Academic self-efficacy has been reported to promote academic achievement directly and also indirectly by increasing academic aspirations and pro-social behavior. Many researchers have reported a direct positive relationship between academic self-efficacy and academic achievement. Self-efficacy had a direct positive relationship demonstrating the importance of self-efficacy for successful learning.

The basic idea behind the Self-Efficacy Theory is that performance and motivation are in part determined by how effective people believe they can be the theory is clearly illustrated in the following quote by Mahatma Gandhi:

"If I have the belief that I can do it, I shall surely acquire the capacity to do it even if I may not have it at the beginning" Mahatma Gandhi

ISSN 2632-9433

Received Jan 10, 2018 / Accepted Jun 20, 2018 / Published Jul 05, 2018 


\section{Literature Review}

According to Bandura (1986), people tend to avoid situations they believe exceed their capacities, but they are willing to undertake and perform those tasks or activities they consider themselves to be capable of accomplishing successfully. The second fundament refers to the fact that students set individual goals that become their personal standards for assessing their performance.

According to Mento et al., (1992), internal rewards for goal attainment, in other words, the satisfaction you receive due to performing a successful task, can drive stronger influences on effort and achievement than external rewards such as grades or academic performance.

Collins (1982), demonstrated in a clear way the importance of self-efficacy beliefs and skill application on academic performance. The study showed that people may perform poorly on tasks not necessarily because they lack the ability to succeed, but because they lack belief in their capabilities.

Yip \& Chung (2005), has also found that the perceived self-efficacy increases academic achievement in a direct and an indirect way, by influencing individuals' goals. Self-efficacy, together with the goals, influences academic performance. Individuals with a high level of self-efficacy assign higher goals to them and exercise more effort and willingness to have them accomplished.

Locke \& Latham (1990), defined that the more challenging the goals are, the more motivation they stimulate. A high level of motivation and willingness bring about higher academic accomplishments.

\section{Research Method}

\section{Statement of the Problem}

Every educational institution needs to understand its internal strength and weakness, and external opportunities and threats. In MLN (MUKAND LAL NATIONAL) COLLEGE YAMUNA NAGAR students come from different states with different backgrounds, thus, their self-efficacy may differ.

\section{Objectives}

The purpose of this study was

a) To study the relationship between self-efficacy and academic performance of students of all streams of MLN College Yamuna Nagar.

b) To assess any significant difference between the mean scores of self-efficacy \& academic performance on the basis of demographic variables i.e. age, gender, and course.

For this study the hypotheses framed are

H1: There is a significant relationship between self-efficacy and academic performance.

$\mathrm{H} 2$ : There is a significant relationship between self-efficacy and academic performance among students varied by gender.

H3: There is a significant relationship between self-efficacy and academic performance among students varied by age.

H4: There is a significant relationship between self-efficacy and academic performance among students varied by course.

\section{Results and Analysis}

\section{Research Design}

In order to achieve the objectives and the stated corresponding hypotheses, the following plan of the study has been followed.

\section{Population}

The population is all the students enrolled in Different courses offered by MLN College Yamuna Nagar constituted the target population for the present study. 


\section{Sample Size}

A sample from the concerned population is drawn for the purpose of data collection. Nonprobability sampling method is used to gather data from Different areas viz B.com, M.com, B.B.A, B.A, M.A. A sample size of 130 respondents was gathered from these areas.

\section{Sampling Method}

The sampling methodology used is that of convenience sampling.

\section{Research Instruments}

Questionnaire method was used to collect responses. A printed questionnaire was distributed among the students of MLN College Yamuna Nagar for gathering data. This questionnaire measures student's expectations that they can perform competently across a broad range of situations that are challenging and require effort and perseverance. The instrument consists of 20 items and the participants were asked to rate the degree to which each item applies to them on a scale ranging from - not at all true(1) to exactly true(4). For the summary score, the item scores are summed up.

\section{Data Collection Method}

The type of data that was used for the study was primary data. The primary data were collected using questionnaire so as to enable the researcher to obtain accurate and adequate information relating to the research work. Primary data are those which are collected for the first time and are always given in the form of raw materials and originals in character. The questionnaire was circulated to 200 students out of which 130 responded. So the response rate was 65 $\%$.

\section{Data Tools and Techniques}

Statistical tools are the basic measures, which helps in defining the relationship between different items, present, past and future trend of the future trend of the particular business etc. A wide variety of statistical tools are available and any of them can be used by any businessman depending upon the nature of his trade. Statistical tools are (classification):

a) Correlation Analysis

b) t-test analysis

\section{Limitations of the Study}

The prime difficulties which researcher has faced in the collection of information are discussed below:

a) Time constraint: The time period for carrying out the research has been limited as a result of which many facts have been left explored.

b) Limited sample size: The sample size was very small due to which the findings could not be generalized.

c) The unwillingness of respondent: While the collection of the data many employees were unwilling to fill the questionnaire. They have taken this as an unproductive activity.

d) Limited area for research: The area for the study has been only in MLN College Yamuna Nagar, which is quite a small area to represent the whole population.

e) Respondents' bias: Due to biases on the part of respondents, data collected may have been affected which further reduces the credibility of the findings.

\section{Data Analysis}

Objective 1: To study the relationship between self-efficacy and academic performance of students of all streams of MLN College Yamuna Nagar. 


\section{Correlation Analysis}

To test the relation between organizational commitment and employee engagement correlation analysis is used. This tool has applied to measure the degree of relationship between independent variables and dependent variables. Independent variable: - self efficacy, Dependent variable: - academic performance

H1: There is a significant relationship between self-efficacy and academic performance.

Table 1

Correlation

\begin{tabular}{|ll|l|l|}
\hline & Se & Per \\
\hline Se & Pearson Correlation & 1 & $.714^{* *}$ \\
& & .000 \\
& Sig. (2-tailed) & 130 & 130 \\
\hline N & Pearson Correlation & $.714^{* *}$ & 1 \\
& Sig. (2-tailed) & .000 & \\
& N & 130 & 130 \\
\hline
\end{tabular}

**. Correlation is significant at the 0.01 level (2-tailed).

Interpretation:

As shown in the Table no 1, after applying the Pearson's product relation, the value of $r$ has come out to be .714 $(\mathrm{n}=130, \mathrm{p}<0.01$ level) which means that there is a significant relationship between self-efficacy and academic performance. Hence the hypothesis is accepted.

Objective 2: To assess any significant difference between the mean scores of self-efficacy \& academic performance on the basis of demographic variables i.e. age, gender, and course.

In order to achieve the above objective independent sample t-test has been applied.

$\mathrm{H} 2$ : There is a significant relationship between self-efficacy and academic performance among students varied by gender.

Table 2

Group Statistics

\begin{tabular}{lllllrl}
\hline Gender & & Mean & $\begin{array}{l}\text { Std. } \\
\text { Deviation }\end{array}$ & t & $\begin{array}{l}\text { Sig. (2- } \\
\text { tailed) }\end{array}$ \\
\hline Se & Male & 88 & 2.9106 & .39662 & -1.919 & .057 \\
& Female & 42 & 3.0393 & .25637 & -2.223 & .028 \\
\multirow{2}{*}{ Per } & Male & 88 & 73.9330 & 6.71358 & -3.133 & .002 \\
& Female & 42 & 77.5500 & 4.76201 & -3.526 & .001 \\
\hline
\end{tabular}

Table 2 shows a total number of sample size collected was 130 out of which $88(67.69 \%)$ were male respondents and $42(32.3 \%)$ were female respondents. The majority of the participants were male students. Female respondents have scored higher mean in academic performance as well as self-efficacy. Female students have a better academic performance as compared to male students. So, there is a significant difference between the academic performance of male and female.

\section{Academic performance}

The independent sample t-test conducted to compare the difference in academic performance of male and female respondents. The study shows a significant difference in the mean score of male $(\mathrm{M}=73.93, \mathrm{SD}=6.71)$ and female $(\mathrm{M}=77.55, \mathrm{SD}=4.76)$ students; $\mathrm{t}(129)=-3.526, \mathrm{p}=0.001$. It can be inferred from the results that there is a significant difference between academic performances on a gender basis. 


\section{Self-efficacy}

The independent sample t-test conducted to compare the difference in self-efficacy of male and female respondents. The study shows a significant difference in the mean self-efficacy of male $(\mathrm{M}=2.91, \mathrm{SD}=.396)$ and female $(\mathrm{M}=3.03$, $\mathrm{SD}=.256$ ) students; $\mathrm{t}(129)=-2.223, \mathrm{p}=0.028$. It can be inferred from the results that there is a significant difference between self-efficacies on a gender basis.

In the light of the hypothesis, it was found that there is a significant relationship between self-efficacy and academic performance varied by gender. Hence the hypothesis is accepted.

H3: There is a significant relationship between self-efficacy and academic performance among students varied by age.

Table 3

Group Statistics

\begin{tabular}{lllllll}
\hline & Age & N & Mean & Std. Deviation & T & Sig (2-tailed) \\
\hline Se & below 21 & 38 & 2.9855 & .30106 & .675 & .501 \\
& above 21 & 92 & 2.9384 & .38428 & .747 & .457 \\
Per & below 21 & 38 & 75.7421 & 5.09343 & .736 & .463 \\
& above 21 & 92 & 74.8370 & 6.82678 & .830 & .409 \\
\hline
\end{tabular}

\section{Academic performance}

The independent sample t-test conducted to compare the difference in academic performances of the students of age below 21 and above 21. The study doesn't report any significant difference in the mean score of students below 21 $(\mathrm{M}=75.74, \mathrm{SD}=5.09)$ and students above $21(\mathrm{M}=74.83, \mathrm{SD}=6.82)$ students; $\mathrm{t}(129)=.736, \mathrm{p}=.463$. It can be inferred from the results that there is a significant difference between academic performances on an age basis.

\section{Self-efficacy}

The independent sample t-test conducted to compare the difference in self-efficacies of the students of age below 21 and above 21. The study doesn't report any significant difference in the mean score of students below $21(\mathrm{M}=2.98$, $\mathrm{SD}=.30)$ and students above $21(\mathrm{M}=2.93, \mathrm{SD}=.38)$ students; $\mathrm{t}(129)=.675, \mathrm{p}=0.501$. It can be inferred from the results that there is no significant difference between self-efficacies on an age basis.

In the light of the hypothesis, it was found that there is no relationship between self-efficacy and academic performance varied by age. Hence the hypothesis is rejected.

H4: There is a significant relationship between self-efficacy and academic performance among students varied by course.

Table 4

Group Statistics

\begin{tabular}{lllllll}
\hline & course & $\mathrm{N}$ & Mean & Std. Deviation & $\mathrm{T}$ & Sig (2-tailed) \\
\hline Se & Ug & 45 & 2.9562 & .30750 & .093 & .926 \\
& $\mathrm{Pg}$ & 85 & 2.9500 & .38868 & .100 & .921 \\
Per & $\mathrm{Ug}$ & 45 & 75.4000 & 5.10882 & .388 & .699 \\
& $\mathrm{Pg}$ & 85 & 74.9435 & 6.95945 & .426 & .671 \\
\hline
\end{tabular}

\section{Academic performance}

The independent sample t-test conducted to compare the difference in academic performance in the undergraduate and postgraduate students. The study doesn't report any significant difference in the mean score of undergraduate students $(\mathrm{M}=75.4, \mathrm{SD}=5.1)$ and postgraduate students $(\mathrm{M}=74.94, \mathrm{SD}=6.95) ; \mathrm{t}(129)=.093, \mathrm{p}=.926$. It can be inferred from the results that there is no significant difference between academic performances on course basis. 
Self-efficacy

The independent sample t-test conducted to compare the difference in academic performance in the undergraduate and postgraduate students. The study doesn't report any significant difference in the mean score of undergraduate students $(\mathrm{M}=2.95, \mathrm{SD}=.30)$ and postgraduate students $(\mathrm{M}=2.95, \mathrm{SD}=.38) ; \mathrm{t}(129)=.388, \mathrm{p}=.699$. It can be inferred from the results that there is no significant difference between self-efficacies on course basis.

In the light of the hypothesis, it was found that there is no relationship between self-efficacy and academic performance varied by course. Hence the hypothesis is rejected.

\section{Conclusion}

1. H1: There is a significant relationship between self-efficacy and academic performance.

From the study, we found that there is a significant relationship between self-efficacy and academic performance of the students. So the research hypothesis is accepted.

2. H2: There is a significant relationship between self-efficacy and academic performance among students varied by gender.

The results indicate that there is a significant relationship between self-efficacy and academic performance among students varied by gender. So the hypothesis is accepted.

3. H3: There is a significant relationship between self-efficacy and academic performance among students varied by age.

The results indicate that there is no significant relationship between self-efficacy and academic performance among students varied by age. So the hypothesis is rejected.

4. H4: There is a significant relationship between self-efficacy and academic performance among students varied by course.

The results indicate that there is no significant relationship between self-efficacy and academic performance among students varied by course. So the hypothesis is rejected.

The primary objective of the present study was to examine whether there is any relation between self-efficacy \& academic performance or not. The analysis \& interpretation part of the study clearly signified that there exists a significant relationship between self-efficacy and academic performance.

The other objective was to find whether there is a significant difference between the mean scores of self-efficacy $\&$ academic performance on the basis of demographic variables i.e. age, gender, and course. The results indicate that there is a significant relationship between self-efficacy and academic performance on the basis of gender, but there is no relationship according to age and course.

Since student self-efficacy beliefs were found to be significantly and positively related to their academic performance in this study, the importance of self-efficacy's influence on academic performance cannot be underestimated. Therefore as student self-efficacy and academic performance are highly connected, educators and counselors should identify students with low self-efficacy and then implement methods to raise the low student selfefficacy levels.

\section{Recommendations}

The primary factors that determine self-efficacy such as enactive mastery experience, vicarious experience, verbal persuasion, and physiological and emotional states are prime targets on which educators and counselors should focus their efforts. Additional areas that can be addressed to help increase student self-efficacy would be goal-setting, rewards and active learning. Finally, the following recommendations are forwarded:

a) Teachers should be responsible for their students to enhance students self-efficacy.

b) Counselors and educators should give continuous advice and develop techniques that help lower anxiety and reduce stress, to increase student's self-efficacy.

For further research, it is necessary to consider the following issues:

a) Control of extraneous variables is advised. For example, factors which may influence academic achievements such as educational background, aptitude, attitude, motivation, and past academic achievement were not controlled in this study. 
Measuring different disciplines (i.e. B.Sc., M.Sc., B.C.A etc) and comparing their self-efficacy is also recommended so that a broader view comes in picture.

\section{Acknowledgements}

The author would like to thank the editor for their valuable time and advice.

\section{References}

Bandura, A. (1997). Self-efficacy: The exercise of control. Macmillan.

Bandura, A., \& Schunk, D. H. (1981). Cultivating competence, self-efficacy, and intrinsic interest through proximal self-motivation. Journal of personality and social psychology, 41(3), 586.

García, B. B. B., Cedeño, H. A. C., Chica, T. K. M., \& Ríos, Y. R. P. (2018). Characterization of Auditory Disability and Its Relation to the Resilience. International Research Journal of Management, IT and Social Sciences (IRJMIS), 5(2), 15-22.

Mbathia, M. (2005). Cream for law and medicine. The Standard, 6.

McKenzie*, K., Gow, K., \& Schweitzer, R. (2004). Exploring first-year academic achievement through structural equation modelling. Higher Education Research \& Development, 23(1), 95-112.

Mento, A. J., Locke, E. A., \& Klein, H. J. (1992). Relationship of goal level to valence and instrumentality. Journal of Applied Psychology, 77(4), 395.

Meza, A. K. T., Freyre, J. R. A., Cevallos, M. G. O., \& Pico, M. J. M. (2018). Autonomy, Good Humor and Support Networks, Potential of Community Resilience Intervention in People Victims of the Earthquake in the Calderón Parish. International Research Journal of Management, IT and Social Sciences (IRJMIS), 5(1), 1-8.

Momanyi, J. M., Ogoma, S. O., \& Misigo, B. L. (2011). Gender differences in self-efficacy and academic performance in science subjects among secondary school students in Lugari District, Kenya. Educational Journal of Behavioural Science, 1(1), 63-79.

Moritz, S. E., Feltz, D. L., Fahrbach, K. R., \& Mack, D. E. (2000). The relation of self-efficacy measures to sport performance: A meta-analytic review. Research quarterly for exercise and sport, 71(3), 280-294.

Multon, K. D., Brown, S. D., \& Lent, R. W. (1991). Relation of self-efficacy beliefs to academic outcomes: A metaanalytic investigation. Journal of counseling psychology, 38(1), 30.

Mustika, I. W., \& Harini, G. A. (2017). Increasing Education of Family Support for Decreasing Depression Level towards Elderly. International Journal of Health Sciences (IJHS), 1(3), 10-16.

Saxena, A. (2017). The Impact of Nutrition on the Overall Quality of Life Adolescent Girls are Living Across the City of Kota. International Journal of Life Sciences (IJLS), 1(1), 40-48. 